\title{
Project management methods in agriculture
}

\author{
Marina Kholodova ${ }^{1, *}$ and Svetlana Podgorskaya ${ }^{1}$ \\ ${ }^{1}$ Federal State Budget Scientific Institution «Federal Rostov Agrarian Scientific Center» (FSBSI \\ FRARC), Rassvet, Rostov region, Russian Federation
}

\begin{abstract}
The purpose of the research is to substantiate the directions for improving program and target planning in the implementation of state programs based on the principles of project management. The article considers methodological aspects of development and implementation of program planning based on the principles of project management in agriculture in Russia. The article describes the domestic practice of program and target planning in the market conditions of management. The main drawbacks of the software planning tools used in the system of state regulation of agricultural production and development of rural territories are investigated. Special attention is paid to the target orientation of budget allocation. A model of program-target planning based on the principles of project management in agriculture has been developed, which includes a system of elements of strategic state planning. It is proved that the new management tools of state regulation of the agricultural sector, based on the project approach, will allow not only to focus the efforts of authorities at all levels on achieving specific results in the implementation of state programs, but also to transfer agricultural producers of various forms of management to the same level of development.
\end{abstract}

\section{Introduction}

In conditions of modern Russian reality, the role of state planning on the principles of project management designed to address the pressing problems of socio-economic, material-technical, scientific-technological development of the agricultural sector, which contributes to the formation of optimal proportions of its structure taking into account the objectives of a breakthrough scientific / technological and socio-economic development of the Russian economy, as enshrined in the may Decrees of the President of the Russian Federation [1].

The current confrontation of the interests of world powers under the influence of sanctions against Russia, as well as the trends of turbulence in the world and national economy, which represent a new form of global political and economic transformation, requires considering the role of the state in ensuring the competitiveness of agricultural production not from the point of view of the Keynesian school, but from the position of the modern institutional and sociological direction. In this case, the role of the state is reduced to active participation in the formation of the institutional environment through the development and improvement of socio-economic programs. Because the natural selection of institutions

\footnotetext{
${ }^{*}$ Corresponding author: kholodovama@,rambler.ru
} 
does not always leave the best and optimal options. This fact clearly demonstrates the economic policy of the USSR and the ill-conceived, spontaneous economic reforms of modern Russia [2].

Kondrashev K., Maital sh., Remezkov A. A., Seregina S. F., are unanimous in my opinion that through program-target planning, the state intervenes in the life of the market to the extent necessary both to maintain a balanced macroeconomic balance, and to ensure the operation of the competition mechanism or to control those markets where conditions of completely free competition are not feasible [3-5].

\section{Research methodology}

World experience and domestic practice show that the development and implementation of program-oriented planning based on the principles of project management in the agricultural sector allows us to strengthen the target orientation of plans, develop problem-oriented planning, identify certain priorities in solving food supply problems, predict the real picture of the future development of agriculture, invest wisely in priority sectors, and ensure the sustainable development of both agricultural products, raw materials, and food markets, and the national economy as a whole.

From a methodological point of view, design methods of control is the improvement of program planning and reflect the specifics of economic policy, the dynamism of economic processes and conditions for its implementation at certain stages of development, providing an optimal combination of indicative strategic planning of development of the agricultural sector at all levels and economic independence of subjects of agribusiness by sharing responsibility for the achievement of established results.

From the point of view of the system of economic planning for the development of agricultural production, it is necessary that socio-economic development programs Express a well-thought-out strategy and tactics for implementing production and economic activities, contribute to improving the competitiveness of the agricultural sector, are aimed at ensuring food security, increasing the added value of products produced in the agricultural sector, stimulating investment activity in agriculture, implementing an export-oriented strategy in the agro-industrial complex, and fighting poverty, improving the socio-economic standard of living in rural areas, rational use of land.

According to Government decree No. 1050 of October 15, 2016 "On organizing project activities in the Government of the Russian Federation" the project is "a set of interrelated activities aimed at achieving unique results in conditions of time and resource constraints. The socio-economic program in the agricultural sector of the economy in this approach is "a set of interrelated projects and activities United by a common goal and coordinated jointly to improve the overall performance of management" [6].

Projects are developed on behalf of the government. In them, the state sets out the ways and means necessary to obtain the planned results of the development of the agricultural sector of the economy. The levers and incentives for achieving the goals in the projects (programs) are: preferential lending, preferential taxation, state orders, leasing, crop insurance, and financial support for rural producers.

\section{Results}

Programming practice in modern Russia begins with the adoption in 1995 of the Federal law "on state forecasting and programs of socio-economic development", which defined the content of the system of forecasts and programs of socio-economic development of the country and its regions, the main stages of their development, key elements and structure. 
Since then, programs as planning documents have been widely distributed in Russia. For example, over the past decade, about forty Federal targeted programs have been developed and approved. However, most of them were either not implemented or did not bring the expected effect, both due to insufficient financial support, and due to the lack of a sufficiently complete and adapted to the conditions of market structural transformation of the strategic planning system and its corresponding regulatory framework. The ambiguity of understanding of the importance and necessity of state planning of the modern economy at the level of society and in scientific circles created certain difficulties in attempts to revive it. Therefore, for the next two decades, up to 2014, state programs were developed in the absence of an established system of state planning [2;3;7].

The formation of the national system of strategic planning and program approach, in particular, agricultural economists associate with the adoption of the Federal law "on strategic planning in the Russian Federation" in 2014, which provides for the formation of appropriate structures and implementation mechanisms at all levels of management. A complex and multi-faceted set of planning and forecasting documents on key areas of activity proposed in the law, including: goal setting, forecasting, planning for medium-term and short-term periods, programming, did not allow to form the appropriate regulatory and methodological framework for their implementation in the country by 2016. In this regard, the final terms of their development and approval were postponed to a later date $[1,7,8]$.

It should be noted that the first steps of the state in developing the program approach to planning were made much earlier. So, in 2006 by the Ministry of Agriculture under the Federal law "About agriculture development" was developed and implemented the national project "Development of agriculture", implementation of measures which increased investment activity and competitiveness of livestock, increased consumption of basic foodstuffs per capita and stimulated positive dynamics of economic growth in the agricultural sector in the long term.

The national project laid the fundamental Foundation for the formation of the country's first sectoral State program for the development of agriculture for 2008-2012, reflecting in its structure priority goals, benchmarks, indicators for the development of the industry in the medium term and the state's obligations to support agricultural producers. However, due to the lack of proper experience in developing such documents, the first state Program was imperfect both in structure and in the mechanism of financial support.

Thus, with insufficient state support for the agricultural sector (figure 1), only a small part of it was directly provided to agricultural producers, and often indirect support was provided to the banking sector and insurance companies. This is confirmed by the fact that $80.0 \%$ of the subsidies provided in key areas of the state Program were used to reimburse the interest rate on loans. In addition, investments were actively used in high-turnover industries, including pig and poultry farming, while other areas were not properly developed, such as dairy and beef cattle breeding $[9,10]$.

In order to overcome existing shortcomings and improving tools for strategic planning in the system of state regulation of agricultural production, strengthen their integrated and focused within the long-term state Program 2013-2020 was introduced a new mechanism for budget allocation to support economically important regional programs, which were initially tested in the sectors of beef and dairy cattle. A special feature of the new mechanism for allocating budget funds was the fact that financial resources from the Federal budget were allocated to the regional industry program as a whole. This has helped to increase the efficiency of using state support and improve planning and forecasting work at the level of Russian regions. This methodological approach allowed us to structure the state program, highlighting and fixing in its sections the branches and sub-sectors of the agroindustrial complex, which were provided with financial support from the state. 


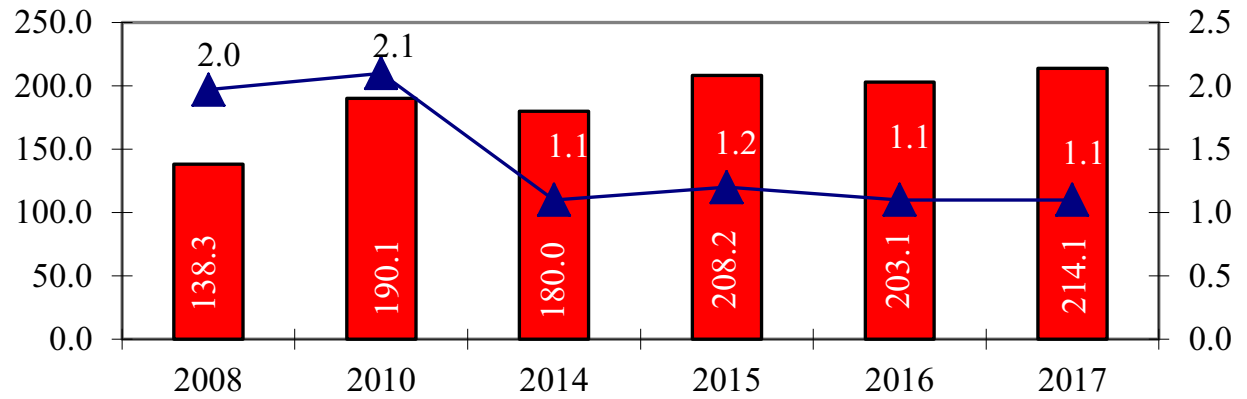

$\square$ Total Federal budget expenditures on agricultural production, billion rubles

- The share of expenditures in support of agriculture in total Federal budget expenditures, $\%$

Fig. 1. Financial support for the program-target approach of agricultural production sectors in Russia

Trends in the globalization of the world economy and Russia's sanctions regime with Western countries have also left their mark on the structure of the state program, which was primarily aimed at ensuring the country's food security and is based on the principles of the food approach.

A special feature of the long-term state program was that it included for the first time the subprogram "Technical and technological modernization, innovative development". The subprograms "Development of beef cattle breeding", "Support of small forms of farming" were also noted as priorities.

However, the new format of the state Program was not without drawbacks. Thus, the fragmented nature of the strategic planning system, the lack of methodological recommendations and experience in developing macroeconomic plans, forecasts and programs forced state authorities at all levels to manage the development of the agricultural production sector in "real time", based on the current situation, excluding the possibility of economic foresight, allowing to act ahead of time. Consequently, the Ministry of agriculture of Russia was deprived of qualitative methods for substantiating long-term scenarios for the development of agricultural production based on forecasting. In addition, according to academician G. Bespakhotnyy, the constant adjustment and inclusion of tactical tasks in the state program caused the need to make changes to the planned activities $[1 ; 2 ; 5]$.

Thus, when adjusting the state program in 2016 , additional goals were identified related to improving the financial stability of agricultural enterprises and sustainable development of rural areas. There was also a transformation of the document structure. for example, the mechanism for crediting agricultural producers, which is the basis of industry subprograms, was separated into two separate subprograms: "Development of the financial and credit system of the agro-industrial complex" and "Promotion of investment activities". There was a sub-program "Export of agricultural products", aimed at increasing the competitiveness of domestic agricultural producers in the world market of raw materials and food and expanding sales markets.

In the edition of the state program in 2017. previously set goals were not only reformulated, but also specified, and changed the vector of their achievement, receiving quantitative estimates. The principles and approaches to subsidies have been updated in the system of state support for agricultural production in Russia. Thus, the main innovations were: consolidation of state support measures based on a "single subsidy" for regions and the mechanism of preferential lending [3]. 
However, the updated principles and approaches to subsidies were not aimed at addressing the main shortcomings in the strategic planning system. For example, the budget resources allocated under the new rules were not coordinated with the regulatory and planned indicators for the development of agricultural production, including in the regions of the Russian Federation, and the potential needs of borrowers.

In 2018, in order to strengthen the target orientation and improve the efficiency of budget spending, the Russian Government approved five state programs as "pilot" for conversion to project methods, including the State program for agricultural development for 2013-2020, extending its validity until 2025 and changing its structure. Thus, the project part includes priority projects of the industry that have received the status of departmental projects: "Development of agricultural industries", "Promotion of investment activity", "Technical modernization", "Export of agricultural products". The process part of the state Program includes areas that support them: "Support for the implementation of programs of the subjects of the Russian Federation in the field of land reclamation", "development of land reclamation", "Sustainable development of rural areas", "program implementation Management", "Provision of General conditions for regulating the development of agriculture", "Scientific and technical support", "Development of the raw material base of light industry enterprises".

The widespread use of the program-target method in planning at the present stage of agricultural production development has become a key direction for improving planning and forecasting at the macroeconomic level.

In particular, the transition to project-based methods of program and target planning opens up new opportunities for certain priority areas of agricultural production. Thus, the project format of program and target planning is a mechanism for managing large-scale tasks, which allows you to coordinate the activities of economic entities in agriculture to achieve certain planned goals aimed at obtaining unique results in conditions of time and resource constraints, and pursuing strategic benefits. The priority objectives of the project management industry must comply with the SMART method, i.e. specific, measurable, achievable, relevant and have a deadline by which they must be achieved [7].

The use of project management tools using the mechanism of state support will allow to focus the efforts of authorities at all levels on achieving concrete results. At the same time, budget support will be provided for projects that correspond to the pace of advanced economic development of agricultural production in accordance with the priority ranking procedure, which encourages the achievement of state Program targets (figure 2).

The new management tools for state regulation of the agricultural sector are based on the significant experience of large commercial domestic and foreign corporations in solving complex problems of production development within the framework of initiating preparation, development and implementation of a project that has its own organizational structure, a coordination center with the distribution of roles and responsibilities, and an appropriate development plan. Project mechanisms at the state level involve integrating the activities of government representatives and agribusiness on the basis of public private partnership. Government representatives working simultaneously in their own division and as part of the project management coordination group help agricultural producers interested in projects to expand their opportunities to develop innovative activities and sell their products based on a combination of project and functional approaches. 


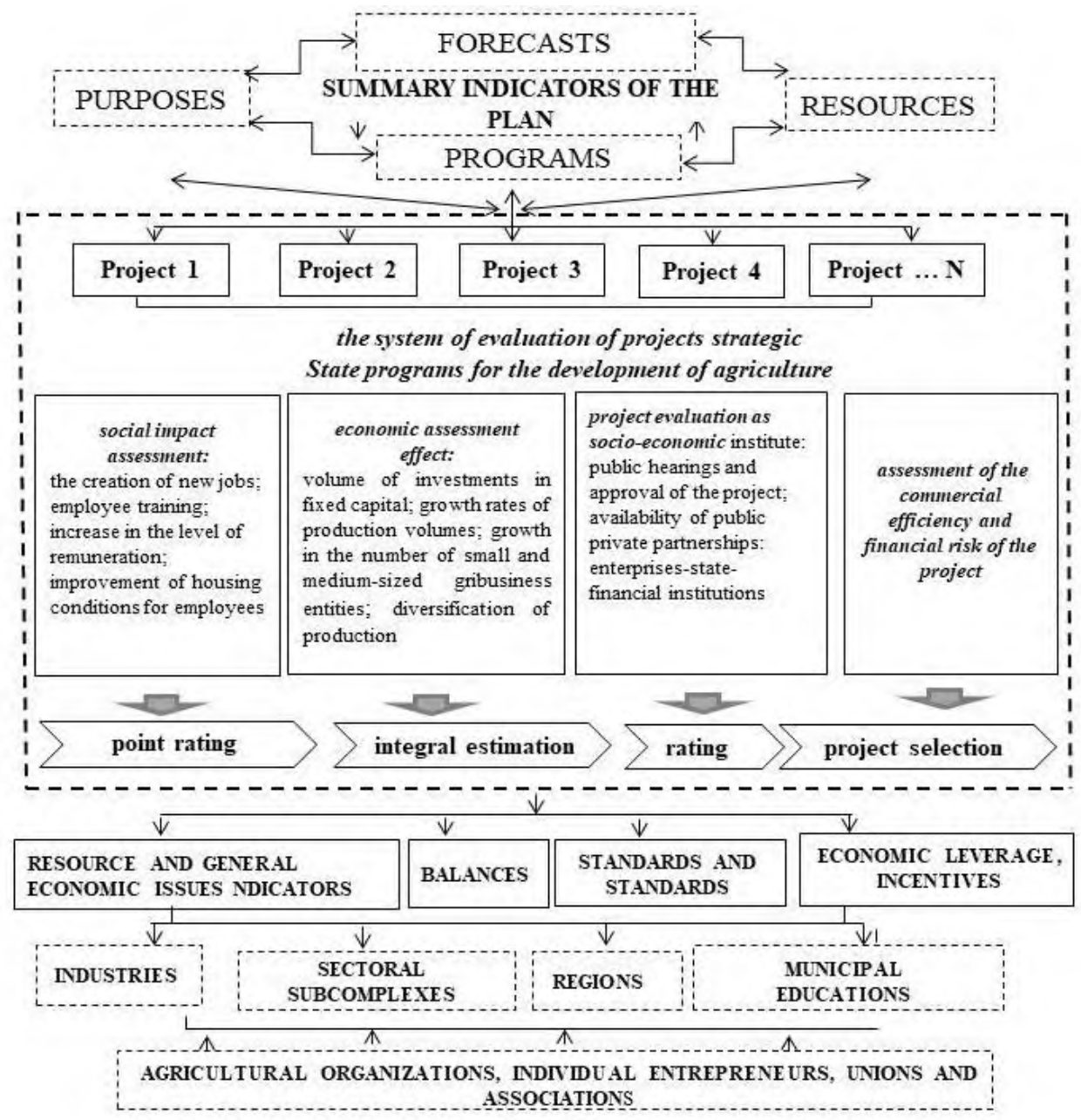

Fig. 2. Model of program-target planning based on the principles of project management in agriculture

It should be noted that such areas of innovation in agriculture as the development of domestic seed production and livestock breeding, production and sale of products within the framework of agricultural cooperation, and large-scale modernization of the material and technical platform of farmers should become key elements of the project management system in the agricultural sector.

In our opinion, the organizational and economic mechanism for allocating budget funds in agricultural production sectors based on project management will contribute to the development of a technological platform that allows developing mechanisms for interaction not only between agricultural producers and state authorities at all levels, but also between credit and financial organizations, universities, scientific institutions, industry unions and associations, and transform the market relations of economic entities with each other. At the same time, industry unions and associations, in cooperation with government authorities, can initiate the development of a portfolio of priority projects, a mechanism for allocating resources, documenting the main stages of design, staff training, and software implementation. 
For example, the "Centrosoyuz" can play an important role in the development of cooperative industrial and economic relations in rural areas, increasing the importance of small agribusiness in ensuring the country's food security [6].

In our opinion, within the framework of the state Program, it is necessary to develop a portfolio of pilot projects and work out the mechanism for their implementation for various natural, climatic and socio-economic conditions. Of scientific and practical interest is the experience of implementing the state Program in the framework of project management in the Belgorod region, on the example of which the Ministry of economic development of Russia worked out project management methods in agriculture. The created model for the implementation of project management, starting from 2009, implements its own approach to the formation of a system of agricultural cooperation at three levels of management "region-district-settlement", based on an administrative resource. The result of the implementation of project management methods was an increase in agricultural production by 1.8 times [7].

In addition to agro-industrial production, the program-target method of state regulation is actively applied to the management of rural development.

The priority national project "development of agriculture" in 2006 can be considered as the beginning of the application of the method of program-target planning to the regulation of rural development. Its further continuation was the Federal target program "Social development of rural areas until 2010", which was extended until 2013, and was succeeded by the Federal target program "Sustainable development of rural areas for 2014-2017 and for the period up to 2020". Since 2020, the state program "Integrated rural development" is responsible for rural development.

In addition to Federal state programs, regional projects are being developed to manage rural social development. For example, 17 targeted rural development programs are being implemented in the Krasnodar territory, and 27 Federal and regional projects are being implemented in the Belgorod region.

O. V. Shimuk identifies three stages in the evolution of rural development management policy in Russia: preparatory (beginning of 2000-2010), stabilization (2010-2018), and integration (beginning of 2019 To our time). Each stage differs in the goals and objectives of development, as well as the preferred methods of managing rural development. While the first two stages used the program-target approach and methods of strategic planning, at present public administration is based on the introduction of project management as a continuation of the program-target method.

Management of rural development today is based on complex approach to the arrangement of settlements, since it is known that the level of competitiveness of the territory is determined not only by the state of the economy, but largely the development of its human potential, the basis for the formation of which is housing, improvement of rural settlements, security services, education, health, culture, sports, development of engineering and transport infrastructures [8-10].

The sub-program "Sustainable rural development for 2014-2017 and for the period up to 2020 " was the main tool of the state policy to support the social development of rural areas. By the end of 2018, out of the 22 targets of the sub-program, the planned values were reached for 20 positions, and the implementation of activities from the allocated funding amounted to $95.9 \%$, which indicates a high efficiency of the project implementation.

During the implementation of the program, the following indicators of rural social infrastructure development were achieved: General education institutions with a capacity of 105.8 thousand places, cultural and leisure institutions-24.6 thousand places, district and district hospitals -6.1 thousand places, outpatient clinics with a capacity of 7.5 thousand visits per shift, paramedic and obstetric stations - 751 units, sports facilities and playgrounds-304 units. 
However, resource support program activities does not provide the pace of development of housing, social and engineering rural infrastructure, road network, necessary for the implementation of serious qualitative changes in the living conditions of the rural population.

Despite the generally successful practice of implementing the program-target method of managing rural development, the state of the rural social sphere continues to be unsatisfactory, and often crisis-like, and does not change dramatically [10;11].

The unemployment rate in rural areas has remained stable for many years and is almost twice as high as in urban areas ( $8 \%$ vs. $4.3 \%$ ). The rural population continues to decline (by $1.3 \%$ in 2018). The level of development of social infrastructure has remained at the same level for several years. The monthly salary of agricultural workers is only $65.6 \%$ of the average for the economy.

It should be noted that in 2013-2018, the share of budget funding for rural social development under the subprogram ranged from $4.6 \%$ to $6.8 \%$ of all direct state support for agriculture in Russia, so more than $90 \%$ of subsidies were directed to support the agricultural economy.

Thus, initially, the subprogram could not have a significant impact on the level of improvement of rural areas and the provision of social services to villagers. The main funding of state support was directed to the production of domestic agricultural products.

In order to implement the state policy on sustainable development of rural areas, an important task of the government is to create an effective institutional environment that ensures the integrated development of these administrative-territorial entities. Among the factors that ensure an effective institutional environment for sustainable rural development, we highlight the updating and harmonization of the legislative framework. At the same time, one of the main problems of state regulation remains the creation of a system for coordinating management actions at the municipal, regional and national levels.

Many researchers note that the legal framework for regulating integrated rural development has often been transformed and adjusted [12], both in terms of defining goals and objectives, and in terms of achieving target indicators and funding volumes, which negatively affected the results of the state program implementation.

Figure 3 shows the subroutine's adjustments for targets. In 2015, in the new version, all planned target values were reduced by an average of $30 \%$, with the exception of "Introduction of paved public roads, thousand km".

In the 2017 edition, the target values were increased, however, compared to 2013, the decrease was $10 \%$, and, for gas and water supply, it was $20 \%$.

A new stage of state management of rural development is the state program "Integrated rural development". 


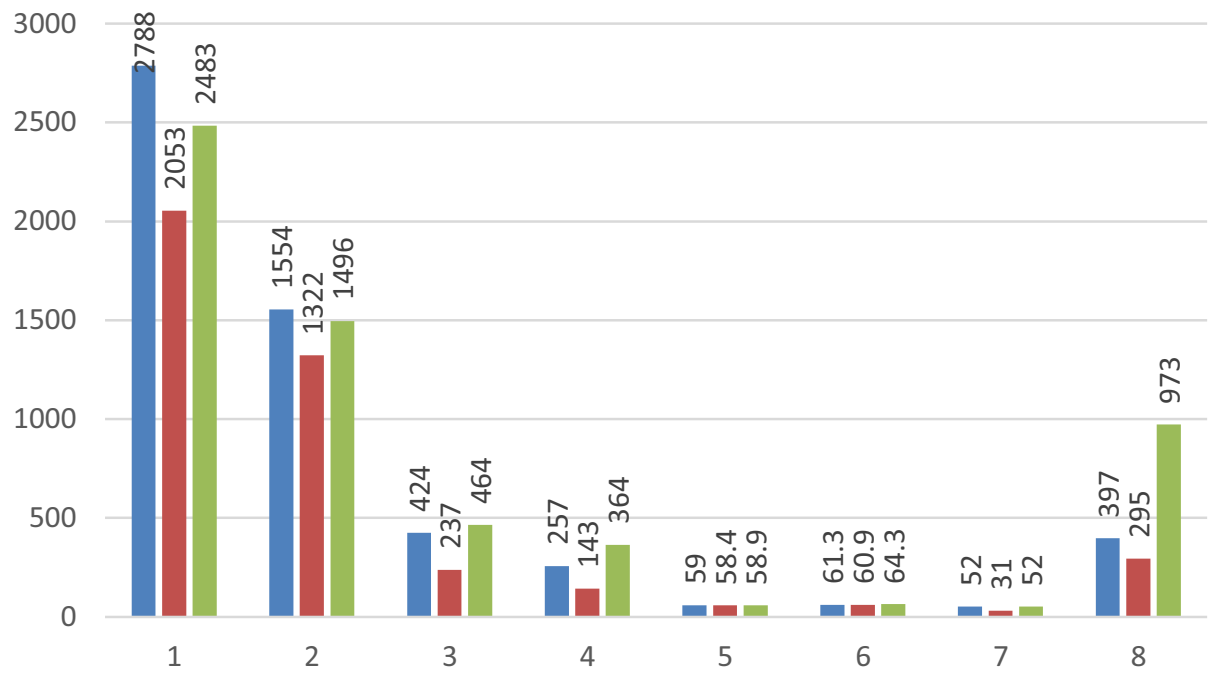

nevision from 15.07.2013 Revision from 16.01.2015 nevision from 13.12.2017

1. Introduction of housing for citizens in rurc areas, thousand $\mathrm{m}^{2}$

2. including for young families and young professionals, thousand $\mathrm{m}^{2}$

3. Entering paramedic and midwifery points and (or) doctors ' offices, units.

4. Introduction of planar sports structures., thousand $\mathrm{m}^{2}$
5. Gasification of residential premises with natural gas in rural areas, $\%$

6. Level of provision of drinking water to the rural population, $\%$

7. Rural settlements equipped for complex residential development, units.

8. Grants, units.

Fig. 3. Main adjustments of the sub-program " Sustainable rural development for 2014-2017 and for the period up to $2020 "$

The state program consists of project and process parts. The project part consists of five departmental projects (DP), and the process part includes three departmental target programs (DTP) (figure 4). 


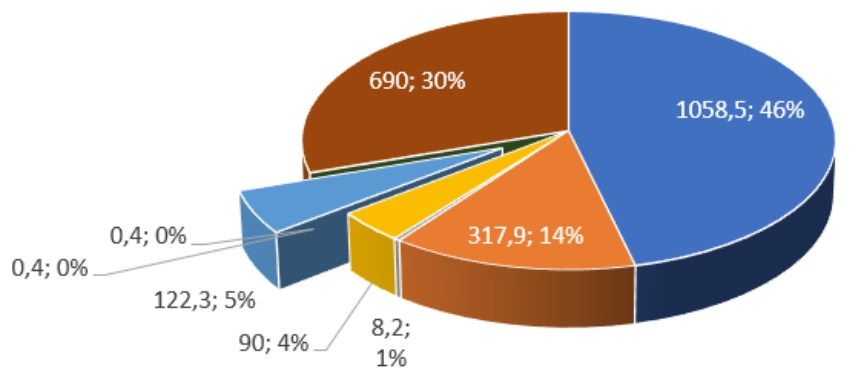

- DP «Development of housing construction in rural areas and improving the level of home improvement»

- DP «Promotion of rural employment»

- DP «Development of engineering infrastructure in rural areas»

- DP «Development of transport infrastructure in rural areas»

- DP «Improvement of rural areas»

- DTP «Ensuring state monitoring of rural areas»

- DTP «Analytical and informational support for integrated rural development»

- DTP «Modern appearance of rural areas»

Fig. 4. Structure of financing of the state program "Integrated rural development", billion rubles.

The key indicators of the program are approved as follows: increasing the ratio of rural and urban incomes from $68 \%$ in 2018 to $80 \%$ in 2025 , stopping the outflow of population from the village, increasing the level of housing improvement, and preserving small rural settlements [14].

The new project of state management of rural development has several fundamental differences from the previous program: the first - a significant increase in budget funding, the second-a radical change in the way it is distributed, and the third-the transition to project management of the implementation of state program activities.

The Federal budget and extra-budgetary sources play a dominant role in the structure of financial support (figure 5).

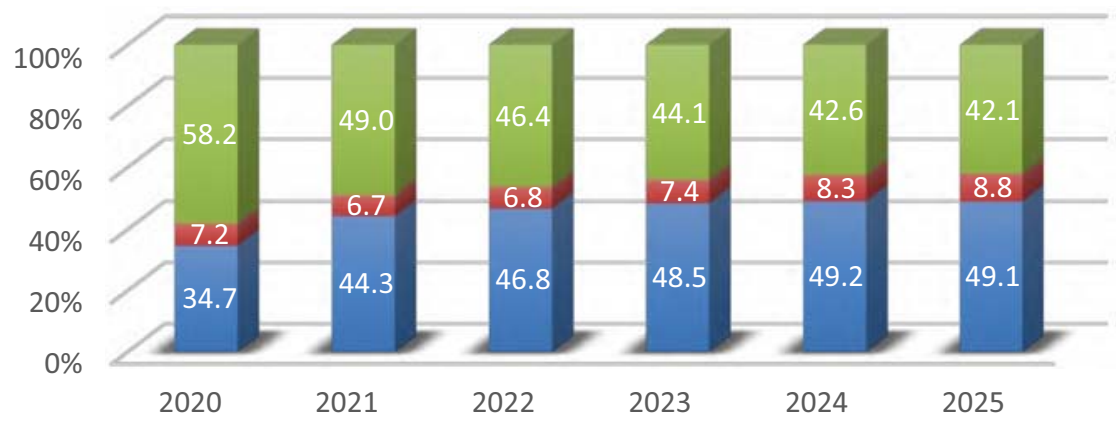

- Funds from extra-budgetary sources

Funds of budgets of subjects of the Russian Federation and local budgets

Federal budget funds

Fig. 5. The structure of financing of the state program «Integrated development of rural areas» according to sources 
However, due to the economic situation as a result of the pandemic and falling prices for hydrocarbons, the government plans to adjust funding for the main state programs. In particular, the most significant reduction will fall under the state program for integrated rural development. Instead of 2.3 trillion rubles, 1.49 trillion rubles are expected to be allocated for its implementation until 2025. At the same time, experts estimated that, given the state of rural areas, even the originally planned amount was clearly not enough.

Due to the decrease in funding, the values of the target indicators were changed as a result of the implementation of the state program by 2025 (figure 6).

The reduction in the target indicators is primarily due to a reduction in financial support from the Federal budget, which decreased from 79.2 to 35.9 billion rubles in 2020 .

The relevance of implementing the project approach for public administration is laid down in the basic goals of its implementation: achieving the planned results in a shorter time; more efficient use of budget resources at all levels; rationality and reasonableness of decision-making; improving the quality of communications between departments and their structural divisions, Executive bodies of state power with business structures at all levels; reducing the level of corruption in the country [13]. ciples:

Project management of rural development should be based on the following basic prin1) result orientation (formulation of a clear specific goal, availability of targets and their indicative values);

2) a systematic approach to the organization of the management process (distribution of competencies and levels of responsibility among the project team members);

3) openness (involving the local population and representatives of the business community in project activities);

4) flexibility of the project management system (implementation of the AGILE systemapplication of iterative task execution, interactive interaction of team members, rapid response to changes);

5) continuous improvement (focusing on the best Russian regional practices, using the best technologies, and continuously improving the professional competencies of the project team).

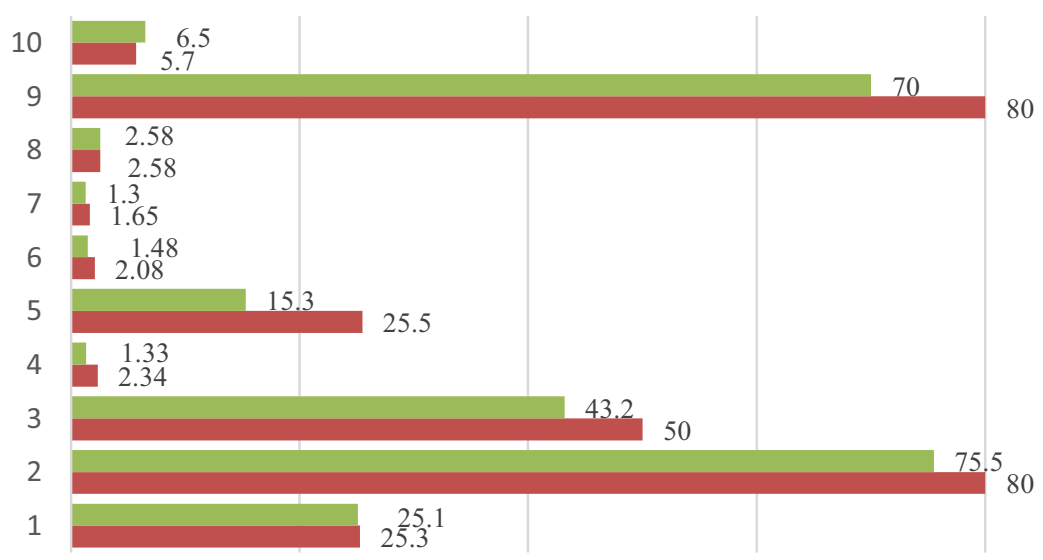

Editorial draft 2020 Decree of the government of the Russian Federation from 31.05.2019 № 696

1. Maintaining the share of the rural population, $\%$

2. Ratio of available resources of rural and urban households, $\%$

3. Percentage of comfortable homes in rural areas, $\%$

4. Housing commissioning, $\mathrm{mln} \mathrm{sq} \mathrm{m}$ 
5. Providing rural families with housing, thousand families

6. Creation of gas distribution networks, thousand $\mathrm{km}$

7. Creation of water pipes, thousand $\mathrm{km}$

8. Creation of paved roads, thousand $\mathrm{km}$

9. The employment rate of the rural population, $\%$

10. The unemployment rate of the rural population, $\%$

Fig. 6. Changes in indicative indicators of the state program "Complex development of rural territories"

The project approach will shift the focus of government activities from executing orders to achieving results. The project management methodology allows you to connect the resources of interested Federal Executive authorities to this issue: the Ministry of health, the Ministry of Education, the Ministry of construction, the Ministry of energy, and the Ministry of industry and trade.

The introduction of project management and project offices contributes to the distribution of responsibilities and powers, improving interagency interaction, efficiency of information flows for making informed management decisions, increasing the openness and transparency of projects and activities, which, in turn, leads to an increase in the efficiency of resource use, reducing project implementation times and reducing costs.

At the same time, the implementation of the project approach to rural development management revealed a number of problems: the lack of competencies in the field of project management, first of all, among municipal employees, the unwillingness of middlelevel civil servants to make independent decisions and take responsibility for them, and the weak motivation of staff.

The state has formed a legislative and regulatory framework for managing rural development. however, public policy instruments are not fully used, and are primarily focused on ensuring macro-manageability of the regional system, which to a certain extent led to resource dependence on the higher level, reducing the interest of local governments in the formation of municipal policies for rural development.

The locality should be a so-called social cluster with a number of necessary objects. The provision of social infrastructure services to the rural population should be comprehensive, since all the elements of service and their coordinated interaction create a so-called synergistic effect. In the absence or underdevelopment of any services, the opposite effect is created, due to the incompleteness of system formation and sharply reducing the efficiency of the entire reproductive process.

State management of integrated rural development should be based on state social standards. Since the basic conditions, potential of rural areas, and forms of spatial development are significantly differentiated within the country, social standards should be developed at the regional level [15].

The Rostov region has started developing a regional Standard for human social welfare. According to Governor Vasily Golubev, the standard will provide a new quality of life for Donetsk residents. The project is aimed at ensuring equal opportunities and an equal level of living comfort for both urban and rural residents. It should include measures to support families with children, the creation of a special system of medical care for the elderly, providing clean water to residents of all cities and districts, annual increases in public sector salaries, and much more.

\section{Conclusion}

Despite the fact that in Russia, since 2018, there is a process of reorientation of the State program for agricultural development to project management methods, having received the status of "pilot", the mechanisms of program measures do not provide an optimal distribu- 
tion of budget funds and a balance of quantitative and qualitative targets and production and economic indicators with available resources. In this regard, it is necessary to change the target orientation of relations between authorities at all levels of management and economic entities, ensuring the implementation of a systematic approach to the distribution of state support.

The creation of scientific and methodological support for the system of strategic planning in the agricultural sector of the economy, the formation of which is the responsibility of the relevant departments of the management bodies of the agricultural sector, as well as science, will contribute to the more effective development and mutual linking of Federal and regional programs based on the project approach. In this regard, there is a need for scientific justification of the key areas of state regulation of agricultural production and rural development, which allows them to combine into a certain system of methodological approaches and make effective changes to the content of the existing state Program for the development of agriculture or the development of new ones.

\section{References}

1. G. Bespakhotny, Models, systems, and networks in Economics, technology, nature, and society, 2(26), 3-15 9 (2018)

2. G. Bespakhotny, Economy of agricultural and processing enterprises, 1, 19-22 (2016)

3. A. Boldyrev, R. Shepitko, Agrarian scientific journal, 1, 90-93 (2016)

4. M. Slozhenkina, I. Gorlov, M. Kholodova, O. Kholodov, O. Shakhbazova, D. Mosolova, AGRITECH-III-2020 IOP Publishing IOP Conf. Series: Earth and Environmental Science, 548 (2020) doi:10.1088/1755-1315/548/8/082037

5. G. Bespakhotny, V. Fundamental and applied research of the cooperative sector of the economy, 2, 15-20 (2012)

6. S. K. Wegren, Journal of Eurasian Studies, 3(2), 193-202 (2012) doi: 10.1016/j.euras.2012.03.010

7. V. Uzun, N. Shagaida, Z. Lerman, Land Use Policy, 83, 475-487 (2019) doi: /10.1016/j.landusepol.2019.02.018

8. O. Shimuk, Ars Administrandi, 12(1), 44-60 (2020) doi: 10.17072/2218-9173-2020-144-60

9. S. Podgorskaya, A. Podvesovsky, R. Isaev, Control Sciences, 5, 49-59 (2019) doi: http://doi.org/10.25728/pu.2019.5.5

10. S. Podgorskaya, A. Podvesovsky, R. Isaev, N. Antonova, Business informatics, 3(13), 7-19 (2019) doi: 10.17323/1998-0663.2019..7.19

11. N. Antonova, A. Malyuga, M. Tarasova, [et al.], Spatial development of regions of Russia: trends and models: monograph. Rostov-on-Don: Publishing house of LLC "Mini-type", 80 (2019)

12. D. Loginova, A. Strokov, Public Administration Issues, 2, 115-140 (2019)

13. V. Yanovskiy, A. Isaev, A. Nescheret, Administrative Consulting, 7, 8-16 (2018) doi: 10.22394/1726-1139-2018-7-8-16

14. Federal state statistics service of the Russian Federation-URL: https://www.gks.ru/ (Last accessed 13.06.2020)

15. A. Kostyaev, Economics of Agriculture of Russia, 10, 88-103 (2018) doi: $10.32651 / 2070-0288-2018-10-88-103$ 